\title{
CONE).(OES
}

CIÊNCIA E TECNOLOGIA

\section{A GASTRONOMIA CEARENSE COMO FOMENTO AO TURISMO EM FORTALEZA: A VISÃO DOS GESTORES DE AB DOS HOTÉIS MIDSCALE}

\author{
Amaury Gurgel Neto ${ }^{1}$, Susana Dantas Coelho ${ }^{1}$, Carlos GlaubÊnio Cavalcante de Oliveira ${ }^{1}$ \\ , ANNA ÉRIKA FERREIRA LIMA ${ }^{1}$ \\ ${ }^{1}$ Instituto Federal de Educação, Ciência e Tecnologia do Ceará - IFCE \\ <amaurygurgel@hotmail.com><susana.dantas09@gmail.com><glaubeniosh@ hotmail.com> \\ <annaerika@gmail.com> \\ DOI: <https://doi.org/10.21439/conexoes.v14i2.1271>
}

\begin{abstract}
Resumo. Este estudo buscou analisar a estruturação dos cardápios de três hotéis midscale em FortalezaCE na visão dos gestores de alimentos e bebidas (A\&B) destes espaços, no que se refere a inserção da culinária local. Para tanto, foi necessário averiguar se os pratos típicos estão sendo atraentes para os clientes e por fim, analisar a apresentação dos mesmos e sua caracterização. Optou-se pelo método dedutivo, de cunho qualitativo e caráter exploratório. Baseou-se na pesquisa bibliográfica e como instrumento de coleta de dados, utilizou-se um questionário aplicado aos gestores de $\mathrm{AB}$ desses estabelecimentos, entre os meses de dezembro de 2016 e fevereiro de 2017. Como resultado da pesquisa, percebeu-se que embora saibamos da importância da divulgação da cultura cearense como atrativo turístico, ou seja, como fomento ao turismo, os gestores de $\mathrm{AB}$ ainda não estão considerando essa temática relevante, uma vez que os cardápios são planejados fazendo pouca ou nenhuma referência aos pratos típicos do Ceará.
\end{abstract}

Palavras-chaves: Culinária Cearense. Hotelaria. Turismo.

Abstract. This study sought to analyze the structure of the menus of three midscale hotels in Fortaleza$\mathrm{CE}$ in the perspective of the food and beverage managers $(\mathrm{F} \& \mathrm{~B})$ of these spaces, regarding the inclusion of local cuisine. Therefore, it was necessary, to find out if the typical dishes are being attractive to clients and, finally, to analyze their presentation and characterization. It was used the deductive, qualitative and exploratory method, based on bibliographic research and using a questionnaire as a data collection instrument applied to the FB managers of these establishments, between the months of December, 2016 and February, 2017. As a result of the research, it was noticed that although it is said of the importance of disseminating Ceará's culture as a tourist attraction, that is, as a promotion to tourism, FB managers are not yet considering this relevant theme, since the menus are planned with little or no reference to the typical dishes of Ceará.

Keywords: Cearense Cuisine. Hospitality. Tourism.

\section{INTRODUÇÃo}

Nas últimas duas décadas, a gastronomia vem ganhando espaço nos cardápios de hotéis midscale $]^{1} \mathrm{em}$

\footnotetext{
${ }^{1}$ Em geral, nas bandeiras econômicas e supereconômicas é oferecido o melhor custo-benefício para o cliente que busca por instalação e serviços básicos, além de um bom atendimento. Nas categorias midscale/upscale estão os hotéis que proporcionam um pouco mais de conforto e requinte nesses quesitos, sendo que o segmento upper scale contempla os chamados "hotéis de luxo", com serviços diferenciados e amplas instalações (STR-G 2017).
}

Fortaleza - CE, devido, principalmente, ao crescente fluxo turístico estrangeiro e doméstico, que vem do Sul e Sudeste do Brasil, a fim de conhecer os atrativos do Ceará. Dentre esses, podemos citar não só as belezas naturais mas também, o patrimônio histórico-cultural do Estado, onde a culinária regional se insere e representa o povo cearense e sua memória.

Alguns autores, em busca de estudar os hábitos alimentares e receitas cearenses, vem pesquisando a inser- 
ção da culinária local nos cardápios dos restaurantes da cidade, mas não foram encontradas pesquisas realizadas em hotéis da capital. Diante disso, compreendendo a gastronomia regional como reveladora dos costumes, hábitos e tradições de um povo à medida que mostra formas particulares de cozer pratos regionais com técnicas e ingredientes próprios da região, surge um questionamento que margeia a pesquisa: os hotéis de Fortaleza inserem pratos típicos do Ceará em seu cardápio a fim de apresentar a cultura local aos visitantes?

Para responder a tal questionamento, buscou-se analisar a estruturação dos cardápios de três hotéis midscale em Fortaleza - CE na visão dos gestores de alimentos e bebidas (A\&B) destes espaços, no que se refere a inserção da culinária local e de uma forma mais específica, averiguar se estes pratos típicos estão sendo atraentes para os clientes e por fim, analisar a apresentação dos mesmos e sua caracterização.

Como metodologia, optou-se pelo método dedutivo, de cunho qualitativo e caráter exploratório. Buscou-se a pesquisa bibliográfica por meio de livros da área, artigos científicos, dissertações de mestrado e teses de doutorado. Como instrumento de coleta de dados, utilizouse um questionário aplicado aos gestores de A\&B desses estabelecimentos, entre os meses de dezembro de 2016 e fevereiro de 2017.

A pesquisa foi estruturada em sessões, denominadas de Introdução, onde fez-se uma explanação geral sobre o estudo, Fundamentação teórica, baseando-se em autores e pesquisas realizadas acerca do tema, Metodologia, onde explicou-se as etapas da pesquisa, Resultados e discussões, apontado os resultados obtidos, Considerações Finais, com uma conclusão da pesquisa e Referências.

\section{Referencial Teórico}

O Turismo é um setor da economia que envolve recepção de turistas, aeroportos, viagens, traslados, hotéis de luxo, resorts, pousadas, bares, restaurantes, etc. Além de toda esta estrutura, muitos motivos influenciam na escolha do turista por determinado local, entre eles, atrativos naturais e o patrimônio cultural. Dentro disso, a gastronomia se configura como atividade cultural que indica a identidade de um povo, suas tradições e suas preferências alimentares bem como o resgate de sua memória.

Em relação ao Turismo e à Gastronomia, Costa e Santos (2015, p. 5) afirmam que

[...] se estabelece de duas maneiras: a primeira, pela necessidade básica da alimentação - que dá suporte às necessidades de alimentação de turistas e qualquer outro tipo de visitante; e a segunda, ocorre quando a gastronomia é a principal motivação da viagem - alimentos e bebidas, geralmente os típicos, deixam de ser apenas necessidade básica para tornar-se fonte de cultura e entendimento do local visitado (COSTA; SANTOS, 2015. p. 5).

Para Santos (2000), incentivar o consumo de alimentos regionais viabiliza o resgate da relação do homem com o meio ambiente, tendo em vista que a regionalidade revela lócus entre teias de relações sociais, econômicas e culturais. Para o autor, a globalização pode ser responsável pelo enfraquecimento dos Estados nacionais e regiões internas, tornando-as adeptas ao mercado capitalista (SANTOS, 2000).

A cultura alimentar pode ser entendida como um conjunto de hábitos alimentares cotidianos, construídos a partir de elementos tradicionais e de novos traços adquiridos, ou seja, o processo conhecido por miscigenação cultural. Na visão Matta (1993), as preferências e o prazer de comer estão relacionados à comida, aos temperos, o que nos leva a pensar que se vive mais pelo prazer de comer que pela própria sobrevivência (MATTA. 1993).

Assim, falar sobre hábitos e tradições é voltar ao passado, pois os escravos africanos no Brasil eram alimentados com o objetivo de se evitar mortes por fome e incapacidades de trabalho. Muitos, de modo semelhante aos animais domésticos, foram alimentados com restos e sobras (RAMOS, 1934). Dessa tradição, surgiu o uso do azeite de dendê, coco e temperos que incrementaram a culinária brasileira, pois eram típicas da comida afro-brasileira.

Diante desse cenário, visualiza-se no Brasil a predominância rotineira de uma culinária voltada para misturas, como feijão com arroz, feijoada (feijão acrescido de diversas carnes), misturas a base de farinha de mandioca, como pirões de peixe e carne, além de gorduras, ensopados de verduras (como os cozidos portugueses), frituras e assados (como o churrasco, apreciado na região sul do Brasil) e fritadas de peixes com mandioca.

Já as saladas, associadas ao almoço, são mais consumidas nas regiões Sul e Sudeste, herança dos imigrantes europeus, principalmente desde o final do século XIX, com o cultivo do café). Mais tarde, vieram japoneses, poloneses, sírio-libaneses e russos, que somaram suas iguarias às já existentes no país.

Dessa forma, a região Nordeste, por exemplo, se apropriou das misturas de feijão e farinha ou arroz, pirão de farinha e gorduras, carnes (também, vísceras, baço, estômago, fígado), peixes ensopados e fritos. Porém, as verduras geralmente são cozidas o que as caracterizam como subsídios culinários e não como "comi- 
das", como nos hábitos do Sul e Sudeste, regiões influenciadas diretamente por europeus.

Segundo Rocha (2003), a culinária cearense pode ser compreendida como abrangendo três regiões: Sertão, Serra e Litoral. A autora esclarece que cada uma destas regiões possui seus ingredientes e receitas próprias, mas várias receitas podem ser encontrados nas três regiões, a exemplo do baião de dois, da paçoca e da peixada cearense.

Marques (2014) discute a Gastronomia como atrativo turístico no Ceará, assinalando que o turismo tem apoio institucional, com investimentos públicos, e que a gastronomia tem papel relevante nesta indústria, sendo um dos seus principais atrativos. Segundo Marques (2014),

[...] a Gastronomia do Ceará caracteriza-se por sabores marcantes de diversas regiões. Os de alimentos típicos da fauna e da flora, do azedo ao doce, do salgado ao insosso, todos têm sua historia na culinária do local. Litoral, sertão e serra, mistura de alimentos, hábitos, costumes e cultura é que fazem a gastronomia do Cearense. Alimentos exóticos de gosto forte como buchada, panelada ou cuscuz não são apreciados pelos visitantes, são mais atrativos para residentes habituados a pratos exóticos (MARQUES. 2014 p. 43).

Algumas peculiaridades se fazem presentes no paladar cearense, daí a existências de ingredientes subdivididos em algumas regiões do Estado, conforme é mostrado na Tabela 1

O estudo de Oliveira (2015) também merece destaque, uma vez que versou sobre o potencial gastronômico das barracas da Praia do Futuro, em Fortaleza, e sua importância para o turismo, identificando as preferências culinárias nestas barracas e o patrimônio culinário do Ceará. A autora discorre sobre os sabores peculiares das regiões serrana, sertaneja e litorânea do Ceará. Relata, ainda, que a culinária do sertão é fortemente ligada à pecuária e, tendo como fonte o Polo Gastronômico do Mercado São Sebastião, onde pratos como típicos do sertão podem ser degustados à exemplo da panelada, buchada, sarrabulho, cuscuz com carne de sol, entre outros.

Entre os pratos típicos das serras cearenses, a autora destaca o baião de dois, a galinha caipira, o feijão verde com nata, o mungunzá salgado e o cozido cearense, a costeleta de porco guisada e a galinha à cabidela. Especificamente, na região do Maciço de Baturité, de acordo com Maciel, Sousa e Lima (2016), a população reconhece como alimento tradicional da Região, o mugunzá salgado, bastante apreciado pelos indígenas Kanindé de Aratuba e pelos remanescentes de quilombos da Serra do Evaristo, localizada no município de Baturité.
Para ela, o Litoral é região do Estado cuja gastronomia é mais conhecida e que tem como pratos principais a peixada cearense, peixe na telha, peixe à delícia, peixe ao molho de camarão, camarão ao alho e óleo, lagosta ao alho e óleo, lagosta thermidor, moqueca de arraia, caranguejo, caranguejada, casquinha de caranguejo, atolado de caranguejo, patinha de caranguejo e ostra.

Lima (2012) realizou um estudo sobre a emergência de uma cozinha regional no Ceará objetivando compreender os mecanismos sócio-históricos que contribuem para a transformação do espaço local em espaço de memória, propiciando o aparecimento das chamadas cozinhas regionais como marcas de identificação cultural. Para tanto, a autora analisou o Plano de Desenvolvimento Sustentável do Ceará (1995 - 1998) e reportagens veiculadas em jornais sobre a cozinha cearense.

Desse modo, para Costa e Santos (2015), têm-se a gastronomia cearense como o resultado da miscigenação de tradições que resulta na imagem turística do Estado. Para alguns pesquisadores toda essa mistura de ingredientes que resultam nos pratos típicos é algo artificial, tendo em vista atrair os turistas, fazendo com que estes conheçam e saboreiem os costumes gastronômicos de cada lugar ou região. Aqui no Ceará estas preparações ganham outro motivo de existirem, em vista da divulgação dos nossos costumes, mas não somente isso, para melhor se divulgar o Estado e tudo que pode ser oferecido aos turistas. Com toda essa divulgação e crescimento da nossa comida cearense, hoje já se realizam eventos nacionais ou internacionais graças a nossos sabores e temperos, atraindo assim um grande público.

\section{Metodologia}

Para o desenvolvimento da pesquisa optou-se pelo método dedutivo, de cunho qualitativo e caráter exploratório. Buscou-se na pesquisa bibliográfica subsídio teórico, por meio de livros da área, artigos científicos, dissertações de mestrado e teses de doutorado.

Para alcançar os objetivos propostos, utilizou-se como instrumento de coleta de dados, um questionário aplicado aos gestores de A\&B desses estabelecimentos, entre os meses de dezembro de 2016 e fevereiro de 2017. Escolheu-se três hotéis categoria midscale (3 e 4 estrelas) para realizar a pesquisa, tendo em vista a estrutura dos mesmos. Foram realizadas duas (2) visitas de campo para a aplicação dos questionários com os gestores de $\mathrm{A} \& \mathrm{~B}$ desses estabelecimentos. Entrevistou-se ainda, quinze (15) hóspedes, clientes dos restaurantes em questão, onde pretendeu-se averiguar a satisfação destes em relação ao cardápio. 
Tabela 1: Alimentos Mais Consumidos por Região

\begin{tabular}{|c|c|c|}
\hline SERTÃO & SERRA & LITORAL \\
\hline $\begin{array}{l}\text { Carne de sol, paçoca, banana, } \\
\text { carneiro guisado, panelada, } \\
\text { feijão verde, buchada de vísceras } \\
\text { de carneiro, curimatã } \\
\text { e ovas de peixes de açude } \\
\text { e queijo coalho. }\end{array}$ & $\begin{array}{c}\text { Frutas (banana, jaca, mamão, abacate, } \\
\text { fruta do conde, tangerina); aves (jacu pema, } \\
\text { capote, galinha caipira), além de feijões diversos, } \\
\text { cana de açúcar, cachaça, vinhos, licores, } \\
\text { mel de abelha, rapadura, caldos de cana, geleias, } \\
\text { doces de frutas locais, maxixe, quiabo, batata doce, } \\
\text { beiju, carimã, goma, galinha à cabidela, } \\
\text { capote guisado, cozido cearense, baião de dois } \\
\text { com queijo e pequizada. }\end{array}$ & $\begin{array}{c}\text { Peixadas no molho de camarão, } \\
\text { moqueca de arraia, } \\
\text { caranguejada, } \\
\text { ostra e caldo de peixe. }\end{array}$ \\
\hline
\end{tabular}

FONTE: Adaptado de Marques (2014).

O questionário aplicado aos gestores foi composto de seis (6) questionamentos objetivos, sendo quatro (4) com questões de múltipla de escolha e duas (2) com questão aberta, que versaram sobre a importância da inserção de pratos típicos no cardápio, ingredientes, formas, apresentação e diferenciais, além da visão da culinária local como fomento ao turismo. Já o questionário aplicado aos clientes foi focado em questões acerca da qualidade dos pratos consumidos, apresentação, originalidade das receitas, motivação, entre outros itens, somando um total de cinco (5) questões objetivas e de múltipla escolha, com espaço para observações.

Após a tabulação dos dados coletados, fez-se um paralelo com os autores pesquisados a fim de obter uma relação entre o estudado e a realidade apresentada na pesquisa de campo.

\section{Resultados e Discussões}

Os resultados dessa pesquisa estão divididos em dois momentos: a) pesquisa realizada junto aos gestores de $\mathrm{A} \& \mathrm{~B}$ e b) pesquisa realizada com clientes desses restaurantes.

\subsection{Gestores de A\&B dos restaurantes}

Os três entrevistados possuíam o cargo de gerentes de $\mathrm{A} \& \mathrm{~B}$, dois com formação em administração e um com formação em turismo e hotelaria. Em relação a naturalidade, os administradores são cearenses e o hoteleiro, paulista, morando no Ceará há 8 anos.

O primeiro questionamento foi acerca da importância da inserção de pratos típicos cearenses nos cardápios do restaurante e quanto a isso, embora tenham sido unânimes em responder que os três restaurantes sejam tradicionais, ou seja, com gastronomia francesa, buscam incluir pratos regionais em seus cardápios. Enfatizaram saber da importância, principalmente pelo fato de ser um fomento ao turismo cearense, já que os visitantes desejam degustar pratos regionais a fim de conhecer temperos e ingredientes peculiares da região Nordeste.

A segunda questão buscou conhecer a preocupação dos gestores quanto à escolha dos pratos, seus ingredientes e suas formas de preparo, o que se tornou algo preocupante. Dois dos entrevistados, afirmaram ter realizado a escolha dos pratos por serem conhecidos em vários restaurantes, como o Peixe à Delícia e a Peixada Cearense por exemplo, embora não conheçam a história do prato, dessa forma, fizeram alterações no mesmo, a fim de torna-los mais gourmet, enfatizando ainda a necessidade de uma sofisticação do mesmo. Isso mostra a pouca relevância da cultura cearense para esses gestores, que desconhecem de fato a necessidade de manter a caracterização do prato.

Já o terceiro gestor, conhece a história dos pratos, e busca executá-los na íntegra, embora entenda que se fossem mais sofisticados, atrairiam mais os clientes, ou seja, percebeu-se que o objetivo desse gestor não é a difusão dos sabores cearenses, mas principalmente, vender mais.

A terceira pergunta versou sobre a apresentação dos pratos típicos, se levam em consideração os elementos históricos do Ceará. Dois gestores responderam que buscam apresenta-los de forma elegante e atrativa, porém, sem perder a essência e originalidade da receita. Já o terceiro gestor, relatou que os servem com simplicidade, tendo em vista o perfil da cultura cearense. Vale ressaltar que esse gestor não é cearense e que visualiza a cultura nordestina como simples, não devendo ter sofisticação nos pratos. Ressaltou ainda, por meio de uma observação realizada junto à questão objetiva, que a culinária cearense se difere muito da gastronomia francesa, e que isso torna-se um problema na hora de adaptar um prato.

Quanto à essa resposta, causou uma certa preocupação nos autores, tendo em vista que as receitas não 
devem sofrer descaracterizações, embora uma das tendências da atualidade sejam as desconstruções e recriações de pratos clássicos. Porém, essas tendências surgem em restaurantes intitulados gourmets e não em restaurantes tradicionais, que primam por oferecer um serviço tradicional, clássico. O que deixou a preocupação foi justamente o fato de não se preocupar em manter a característica, a peculiaridade da receita.

O quarto questionamento foi sobre a facilidade em aquisição dos insumos, tendo em vista a culinária cearense ser considerada fresca, ou seja, utilizadora de pescados, frutos do mar e laticínios como leite e manteiga. Quanto a esse quesito, foram un6animes em responder que a aquisição dos ingredientes não se configura como problema, pois os fornecedores os possuem sempre que necessária a aquisição.

A quinta pergunta, que foi aberta e se referiu a aceitação dos clientes em relação aos pratos típicos oferecidos nos restaurantes e como fazem esse mapeamento de aceitação. Nesse quesito, dois entrevistados afirmaram que os clientes se sentem satisfeitos com os pratos, com os sabores e que também sentem falta desses pratos em cardápios de restaurantes de shopping centers da cidade e lanchonetes. Além disso, revelaram a necessidade de provas frutas nativas em sucos e doces, que estes ainda são timidamente vendidos na cidade. Já o terceiro gestor, relatou que os clientes se sentem satisfeitos com os pratos típicos oferecidos pelo restaurante mas que estes também procuram pratos exóticos (como chamam por serem na maioria turistas) os pratos típicos das regiões sertanejas, como buchada, panelada, sarrabulho, entre outros, mas que o gestor afirma ser mais difícil a oferta, por se tratarem de pratos que requerem maior tempo de preparo, cozinheiros especializados, estrutura mais apropriada e a logística de aquisição de produtos frescos e in natura como no caso do sangue fresco para fazer o sarrabulho.

E, por fim, o sexto $\left(6^{\circ}\right)$ questionamento objetiva conhecer a visão dos gestores sobre a culinária enquanto fomento ao turismo. Na visão de dois gestores, esta pode fomentar o turismo desde que seja encarada como patrimônio cultural, ou seja, desde que seja difundida como algo da terra, herança daqueles que contribuíram para a formação do povo cearense. Assim, ao conhecer a história dos pratos típicos do Ceará, suas características e importância de manter viva a identidade do povo é que serão motivo de fomento.

A visão do terceiro gestor difere bastante dos outros, uma vez que afirma ser uma culinária mais simples, voltada apenas para os frutos do mar e pescados e para a comida sertaneja, representada pela carne de sol.
O gestor não enxerga a culinária local como fomento ao turismo porque entende que o turista (pelo menos os do hotel em que trabalha) não vêm ao Ceará motivados pela Gastronomia. Porém, os três foram unânimes em responder que esta poderia ser divulgada e difundida por todo o mundo por conter pratos com sabores únicos, como o Peixe a Delícia e Carne de Sol Sertaneja, embora apareçam em outras regiões do Nordeste.

\subsection{Clientes}

O primeiro $\left(1^{\circ}\right)$ questionamento feito aos clientes foi a respeito dos interesses pela cultura cearense no que se refere à culinária local. Dos quinze (15) entrevistados, catorze (14) responderam que possuem interesse na cultura cearense, em especial pela culinária. Somente um respondeu que não e acrescentou que não gosta da comida cearense por achar muita pesada e gordurosa.

A segunda ( $2^{\mathrm{a}}$ ) questão foi voltada para a qualidade dos pratos servidos no restaurante do hotel. Todos foram unânimes em responder que se agradaram bastante do que provaram e que os três oferecem alguns pratos típicos cearenses. Dos quinze (15) entrevistados, cinco (5) acrescentaram que poderiam ter opções de pratos cearenses mais variados, inclusive apresentando a história dos pratos, até como forma de atrair mais na hora da escolha.

$\mathrm{O}$ terceiro $\left(3^{\circ}\right)$ questionamento foi sobre a apresentação dos pratos regionais. Dos quinze (15) entrevistados, doze (12) relataram ser pouco atraente, embora satisfatória. Desses doze (12), cinco (5) relataram a falta de originalidade e caracterização, pois são apresentadas seguindo uma padronização características de todos os pratos do restaurante. A partir daí, pode-se perceber que existe uma negligência por parte dos gestores com a apresentação dos pratos que, deveriam ser apresentados em sua forma original, além de serem atraentes aos clientes.

A quarta ( $\left.4^{\mathrm{a}}\right)$ questão versou sobre a importância da divulgação da cultura cearense, em especial da culinária. Nesse quesito, todos responderam que é de suma importância e 6 acrescentaram que não só da região Nordeste, mas em todos os Estados deveriam ser assim. Afinal, os turistas deveriam sair da localidade conhecedores da cultural do local.

E, por fim, a quinta $\left(5^{\circ}\right)$ questão versou sobre a culinária como fomento ao turismo, onde todos os entrevistados acreditam que essa possa contribuir para atrair novos turistas, desde que esteja presente no momento em que buscam o destino a ser visitado. Ou seja, na hora da decisão pela viagem, essas peculiaridades deveriam estar bem apresentadas em sites, revistas especializadas, 
guias turísticos, entre outros materiais de divulgação.

\section{Considerações Finais}

Após a realização da pesquisa em três (3) hotéis midscale em Fortaleza, percebeu-se que embora saibamos da importância da divulgação da cultura cearense como atrativo turístico, ou seja, como fomento ao turismo, os gestores de $\mathrm{A} \& \mathrm{~B}$ ainda não estão considerando essa temática relevante, uma vez que os cardápios são planejados fazendo pouca ou nenhuma referência aos práticos típicos do Ceará.

Com o crescimento de programas de cunho gastronômico, pode-se perceber que cada dia mais a propagação de receitas regionais chamando a atenção de muitos chefs e cozinheiros, que passam a adaptar suas receitas e cardápios, a fim de agradar e satisfazer as necessidades dos clientes. Porém, quando nos referimos à oferta de pratos clássicos da cultura popular cearense, notou-se uma certa resistência, em um caso específico até um preconceito pela oferta de pratos voltados para a cultura litorânea e sertaneja. Isso se dá, principalmente, pela falta de visão dos gestores, pela estagnação profissional e pelo despreparo em relação às tendências do mercado gastronômico.

Diante disso, cabe aos gestores uma maior compreensão da importância da culinária cearense nos cardápios dos restaurantes dos hotéis, principalmente por difundir a cultura entre visitantes.

\section{REFERÊNCIAS}

COSTA, E. R. C.; SANTOS, M. S. F. Estratégia gastronômica na terra da luz: desvendando a culinária cearense pelo turismo. TURyDES, v. 8, n. 18, p. 1-18, 2015.

MACIEL, T.; SOUSA, M. de; LIMA, A. É

Comunidades tradicionais: saberes e sabores dos indígenas de aratuba aos quilombolas de baturité-ce. Conexões-Ciência e Tecnologia, v. 10, n. 3, p. 63-70, 2016.

MARQUES, M. T. P. A Gastronomia do Ceará como atrativo turístico. Dissertação (Mestrado Profissional em Gestão de Negócios Turísticos) — Universidade Estadual do Ceará, Fortaleza, 2014.

MATTA, R. O que faz do Brasil, Brasil? 1. ed. Rio de Janeiro: Rocco, 1993.

OLIVEIRA, V. A. A Gastronomia das Barracas da Praia do Futuro como Atrativo Turístico em
Fortaleza - CE. Dissertação (Mestrado Profissional em Gestão de Negócios Turísticos) — Universidade Estadual do Ceará, Fortaleza, 2015.

RAMOS, A. O negro brasileiro: etnografia religiosa e psicanálise. 1. ed. Rio de Janeiro: Civilização Brasileira, 1934.

ROCHA, D. Sabores e Saberes do Ceará: Arte Culinária e Fotografia. 1. ed. Fortaleza: Editora D. M. Rocha, 2003.

SANTOS, M. Por uma outra globalização: do pensamento único à consciência universal. 1. ed. Rio de Janeiro: Record, 2000.

STR-G. Um guia para nossa terminologia. 2017. Disponível em: <http://www.str-g.com/resources/ glossary/pt-BR> 